\title{
Letter to the Bditor
}

\section{Serum magnesium level and knee osteoarthritis}

Sora Yasri ${ }^{1}$, Viroj Wiwanitkit ${ }^{2}$

${ }^{1}$ KMT Primary Care Center, Medical Center, Bangkok, Thailand

${ }^{2}$ Haihan Medical University, Tropical Medicine, Haikou, China

\section{Dear Editor,}

The manuscript titled "Serum magnesium level is not associated with inflammation in patients with knee osteoarthritis (OA)" is very interesting. ${ }^{[1]}$ Benlidayi et al. ${ }^{[1]}$ concluded that "although serum $\mathrm{Mg}$ is associated with the radiological severity of knee OA, it is not associated with inflammatory biomarkers including ESR and CRP." Indeed, ESR and CRP are well-known non-specific inflammatory biomarkers, but serum magnesium is not. Although there is an observation on the relationship between serum magnesium and severity, there are many concerns on the effect of other possible comorbidities on serum magnesium level. Obesity and dyslipidemia, which are common in menopausal women with knee OA, are also related to aberrant serum magnesium level. ${ }^{[2]}$

\section{Declaration of conflicting interests}

The authors declared no conflicts of interest with respect to the authorship and/or publication of this article.

\section{Funding}

The authors received no financial support for the research and/or authorship of this article.

\section{REFERENCES}

1. Benlidayı İ ,Gökçen N, Sarpel T. Serum magnesium level is not associated with inflammation in patients with knee osteoarthritis. Turk J Phys Med Rehab 2017;63:249-52.

2. Farhangi MA, Ostadrahimi A, Mahboob S. Serum calcium, magnesium, phosphorous and lipid profile in healthy Iranian premenopausal women. Biochem Med (Zagreb). 2011;21:312-20.

This letter was submitted to the authors of the manuscript; however, not responded. 